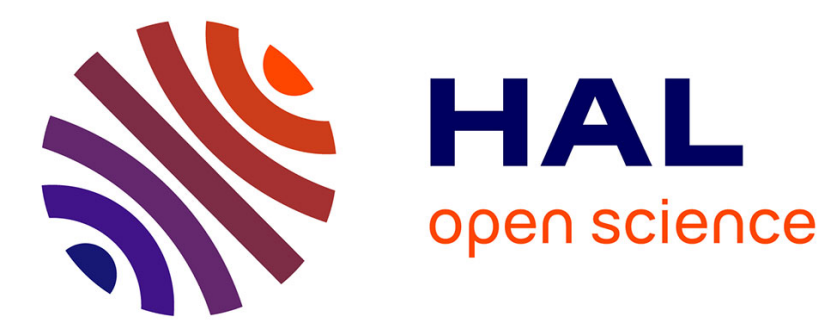

\title{
Integrating progress files into the academic process
} Jackie Haigh

\section{To cite this version:}

Jackie Haigh. Integrating progress files into the academic process. Active Learning in Higher Education, 2008, 9 (1), pp.57-71. 10.1177/1469787407086747 . hal-00571969

\section{HAL Id: hal-00571969 \\ https://hal.science/hal-00571969}

Submitted on 1 Mar 2011

HAL is a multi-disciplinary open access archive for the deposit and dissemination of scientific research documents, whether they are published or not. The documents may come from teaching and research institutions in France or abroad, or from public or private research centers.
L'archive ouverte pluridisciplinaire HAL, est destinée au dépôt et à la diffusion de documents scientifiques de niveau recherche, publiés ou non, émanant des établissements d'enseignement et de recherche français ou étrangers, des laboratoires publics ou privés. 


\title{
Integrating progress files into the academic process
}

active learning in higher education

Copyright (C) 2008 SAGE Publications (Los Angeles, London, New Delhi and Singapore)

Vol 9(1): 57-71

DOI: $10.1177 / 1469787407086747$

ARTICLE

\author{
A review of case studies
}

\author{
JACKIE HAIGH University of Bradford, UK
}

\begin{abstract}
A literature review of published case studies reporting progress file implementation was conducted with the intent of discovering how this is being interpreted and implemented in higher education institutions. The three studies found were analysed using an ideal type categorization developed by Clegg and Bradley (2006), that is, professional, academic or employment. All three case studies are examples of academics learning through experience about the process of personal development planning and how this integrates with current educational provision. As this is not a static process, an activity theory perspective may be a more useful framework to research how this understanding develops in a particular context. Currently the progress file is a contested object, which has not yet fulfilled its potential to place the student and their individual learning needs at the centre of the educational process.

KEYWORDS: higher education, key skills, personal development planning, policy implementation, progress files
\end{abstract}

\section{Introduction}

Higher education institutions in the UK are now expected to have strategies in place which ensure that all students have supported Personal Development Planning (PDP) opportunities during their course of study (Quality Assurance Agency for Higher Education [QAAHE], 2001). This policy originated from a proposal in the Dearing review of Higher Education (National Committee of Inquiry into Higher Education [NCIHE], 1997). The remit of Dearing (NCIHE, 1997) was to provide a vision of Higher Education for the next 20 years. It was the first major review of higher education since 
Robbins (Committee for Higher Education [CHE], 1963) and was commissioned by a Conservative government wanting graduates effectively equipped to promote and service a growing economy. Recommendation 20 (from a total of 93) was as follows:

We recommend that institutions of higher education, over the medium term, develop a Progress File. The File should consist of two elements:

A transcript recording student achievement which should follow a common format devised by institutions collectively through their representative bodies;

A means by which students can monitor, build and reflect upon their personal development. (NCIHE. 1997)

This recommendation was adopted by the Quality Assurance Agency (Quality Assurance Agency for Higher Education [QAAHE], 2000) which set a 2005/6 implementation date for higher education institutions. This implementation date has now passed yet there is still no real compulsion or incentive for academics to 'integrate the development of Progress Files into the academic process' as envisioned by Dearing (2000: 140).

A survey to evaluate the implementation of progress files commissioned by the Department of Education and Skills [DfES] (Brennan and Shah, 2003) reported good progress on the first element of the progress file, namely, the provision of transcripts. These are generally managed by central administration and are often integrated into the development of new student record systems. However provision of the second element, PDP (personal development planning), has been patchy and subject to different interpretations even within institutions. Despite this less than enthusiastic embracing of the new policy and the lack of consensus on key issues (such as assessed/non-assessed, tutor supported or not, employment or education focus) Brennan and Shah (2003) remain cautiously optimistic about the progress of the progress file. The reason for this optimism is the lack of compulsion for academic staff to be involved in the process. They argue that PDP is being introduced where academics see the value of it and for some this means seeing its potential as a radical innovation.

This article seeks to investigate how the integration of PDP into the academic process is occurring in practice. It will first set the historical and political context of this policy through a brief discussion of supercomplexity and widening participation. The theoretical assumptions of the policy are then revealed through an examination of the concept of selfregulated learning. The concept of self-regulated learning focuses attention on individual agency. However it is acknowledged that students can adopt different practices in different contexts. The importance of the context of learning is emphasized from a social practice perspective. This leads to a view of progress files as artefacts which convey a shared meaning of what 
learning is in a particular context. The article then uncovers some detail behind survey data (Brennan and Shah, 2003) by reviewing published case studies on progress file implementation. These case studies are analysed using ideal type categories (Clegg and Bradley, 2006a) and the benefits and drawbacks of the different approaches are highlighted. This leads to a discussion of lessons learnt so far in the implementation of progress files and the implications for further research and development.

\section{Historical and intellectual context}

There is evidence that our society is changing dramatically in terms of knowledge creation and knowledge use. Gibbons (1998), Secretary General of the Association of Commonwealth Universities, makes the case for curriculum change to create more knowledge workers who can access and apply knowledge to solve problems rather than academics to create new knowledge. Broadfoot (1998) describes a postmodern vision of the "learning society' as one 'in which learners are empowered to want, and to be able, to manage their own learning in a highly individualistic manner; where there will be fewer and fewer designated spaces and times, defined outcomes or prescribed bodies of knowledge' (1998: 158). Jackson and Ward (2004), key figures in the development of progress file policy in the UK, see the progress file as higher education's answer to problems posed by the contemporary super-complex world (Barnett, 2000). This is a world in which the only certainty is change and students must prepare themselves for a life of constant adaptation to new circumstances. Higher education in the past has been concerned with preparing scholars able to understand and develop disciplinary knowledge. In contrast, in the post modern world graduates need to be able to work across disciplines, drawing upon and using trans-disciplinary knowledge to work collaboratively and to solve problems. Progress files provide a means whereby students can demonstrate these capacities (Jackson and Ward, 2004).

Barnett (2000) acknowledges the need for new curriculum ideas in this super-complex world but argues that so far the educational response has been an increasing focus on 'performativity' or the attainment of generic skills. He argues that there is too much focus on what the student can do now rather than developing their capacity to engage in a constantly changing environment. This requires a curriculum that seeks to develop self awareness and personal and interpersonal resources. This tension between the need to demonstrate skills to prospective employers and the actual improvement of student learning through a refocusing of the curriculum on student development is a recurring theme in the discussion of the progress file, that is, is it a record of achievement or a tool to support learning? 
Jackson and Ward (2004) draw upon the global context to explain the need for progress files. However there are also national political agendas which have contributed to the pressure on traditional university education. One example is the changing relationship between the academy and the state. It can be argued that university education is now seen as a personal and state investment to secure employability rather than the right of the intellectual elite to higher education. There is a clear government policy in the UK to widen participation in higher education to 50 per cent of 18-30 year olds by 2010 (DfES, 2003). This expansion is linked to the need for a skilled workforce able to function effectively in a knowledge based economy. This vision of graduate abilities is focused more on transferable skills than knowledge of a particular discipline. Thus progress file policy can be seen as politically driven in that the progress file is a means to record and monitor student development throughout their course and to present their skills to prospective employers. This focus on employability does not necessarily conflict with other educational aims such as the development of autonomy (Winch, 2002). However, it can be argued that an emphasis on recording key skills does little to meet the educational needs of an increasingly diverse undergraduate population. What is required is a much clearer focus on the process of learning and adequate resources to provide a scaffold of support to facilitate learner development.

\section{Self-regulated learning}

Boekaerts (1999) argues that perceived failures in the school system, that is, underachievement of the majority and failure to meet employer expectations, have led to the popularity of the concept of self-regulated learning for policy makers and teachers. 'Self-regulation means being able to develop knowledge, skills, and attitudes which can be transferred from one learning context to another and from learning situations in which this information has been acquired to a leisure and work context' (Boekaerts, 1999: 446). Boekaerts (1999) identifies three strands in the concept of self-regulated learning: learning styles, meta-cognitive skills and self-regulation. In relation to learning styles, for example, surface or deep (Entwistle and Peterson, 2004), it is argued that these are not fixed attributes but strategies that students are capable of choosing to use in different contexts. Meta-cognitive skills are the organizing strategies by which students achieve their learning goals and include orienting, planning, evaluating, etc. These skills are well developed in successful learners but they can also be encouraged or taught. Self-regulation is made up of motivational control, that is, the extent to which the student values the task and has confidence in their ability to perform it and volition control, that is, the ability to start, engage and disengage 
from the task. All three aspects are pertinent to the idea of PDP since in PDP the student sets their own learning goals and develops meta-cognitive skills to promote deep learning and thereby successful achievement of goals. Self regulation is seen as the key factor because students may understand metacognitive principles and be capable of deep learning but not be motivated to learn effectively in particular contexts.

Research is focused on individual learning processes but also highlights the importance of the learning context. Social practice theory considers learning as a social rather than individual process, and that learning takes place as the meaning of concepts changes through social interaction. From this perspective self-regulated learning, articulated in PDP artefacts, is not seen as an individual cognitive process but rather as a change in the shared meaning of learning in response to the particular tensions in the current educational system and the impact of the wider environment on this system. Activity theory (Engeström, 2001) suggests that activities are rooted in a social and historical context which impacts on the shared meaning of those activities. This theory, applied to the activity of preparing graduates, suggests that the shared meaning of undergraduate education is underpinned by the university policies and regulations, the tacit understanding of the academic community, the division of labour between academics and students and the artefacts used to articulate this shared meaning.

This rooting of Higher Education activity in a firm socio-historical base limits possibilities for change but, on the other hand, the changing nature of the wider social context, and the prior experience of the undergraduates admitted, create tensions in the system. These tensions may be resolved through the adaptation of tools and artefacts to reflect new priorities. Likewise these new tools and artefacts, particularly if they involve the incorporation of new technologies, may change the meaning or situated knowing about the activity for the actors involved. Progress files, in particular the self development planning aspect, are artefacts which articulate a particular meaning of learning. Thus they are more likely to be successful when introduced by academics who share this understanding. There will be resistance to this artefact from both academics and students if they have a different understanding of what learning is. This reinforces the point about the benefits of non-compulsion made above (Brennan and Shah, 2003). There may also be different meanings attached to particular versions of the progress file in different settings.

A recent international systematic review of PDP activity (Gough et al., 2003) found thousands of examples both in the UK and the USA of academics using reflective practice, learning logs, journals and diaries, etc. with their students but these were not specifically related to progress file implementation. Brennan and Shah (2003) found that less than half of their 
survey respondents had introduced formal policies for the PDP element of the progress file. There have been no studies so far exploring the value of using these diverse practices to build up a progress file of personal development through a higher education programme. The following literature review analyses case studies of progress file implementation. The intent was to discover how this policy initiative is being interpreted and implemented at ground level by academics in higher education institutions. This literature review does not claim to be exhaustive but was systematic and thorough. It seeks evidence of the different versions of the progress file identified by Clegg and Bradley (2006b) and analyses the strengths and weaknesses of these versions.

\section{Methodology}

A literature search included educational databases and Google scholar. The keywords used were 'progress file or personal development planning or recording achievement, and higher education'. The search was limited to English language and the date restriction was from 2000 to 2007 since the focus of interest was the UK experience since the publication of the QAA policy statement (QAAHE, 2000). Case studies describing experiences of implementing progress files in a higher education institution were selected from the hits returned. The rationale for this selection was the intention to investigate responses to the progress file policy per se. Several of the articles retrieved referred to reflective learning or PDP initiatives not directly linked to progress files. There were surprisingly few case studies of progress file implementation.

The three case studies selected describe how progress file policy is being enacted in three different practice settings. They were written by academics with some responsibility for implementing progress files in their department or university. The framework used to analyse these case studies is an ideal type categorization developed by Clegg and Bradley (2006a) who, while not involved with the implementation of progress files directly, investigated the attitudes and approaches articulated by academics associated with PDP in various departments in one university. Three ideal types of PDP were induced from their interview data, that is, professional, employment and academic. These categories are also supported to some extent in survey data (Brennan and Shah, 2003), particularly the academic/employment divide.

Clegg and Bradley (2006a) found that though no ideal type existed in a pure form, each ideal type was associated predominately with different disciplines. For example in their research setting health and educational courses tended to adopt a professional model for PDP which focused on reflection. Sport and Leisure and Engineering courses used an employment 
model which focused on building up a $\mathrm{CV}$ and career management while humanities and social science tended towards the academic model which focused on academic development and meta-cognitive skills. The authors map these different models against concepts of identity and orientation. They considered the course identity in terms of introjection and projection, that is, whether the courses looked inward to the needs of the discipline or outwards to the world of work. They also considered whether the course had a singular orientation, that is, maintained strong subject boundaries or was more generic (Bernstein, 2000; Clegg and Bradley, 2006b).

This ideal type framework (Clegg and Bradley, 2006b) was used as a comparative tool to analyse the three case studies found from the literature review. This tool helps to describe different approaches to the same concept and provides a useful starting point for thinking about PDP and progress files. It is used to disentangle the different philosophies and pedagogical approaches which underpin the implementation of progress files in particular settings. It is particularly appropriate since by chance each of the three case studies found represents a different ideal type.

\section{Case study one: employment}

This case study was written by a progress file tutor charged with introducing progress files university-wide into one institution (East, 2005). The approach focused on skills development, specifically Edexcel skills framework and not the key skills of the Qualifications and Curriculum Authority (QCA) since lecturers were more familiar with the former. The progress file was seen as a tool to aid reflection on skills for learning; to help students identify and take steps to address 'skills deficiency' (2005: 161). The aim was to improve generic learning skills and therefore make the students more employable. In Bernstein's terms (Bernstein, 2000) the identity of the course was projective and the orientation generic. East (2005) identified a difference between the framing of the policy at government level as an information product for employers and the adoption of the policy by academics as a learning process. However the learning achieved is still perceived as generic, not learning in a particular discipline.

East (2005) raises issues that might cause difficulty in a one-solution, university-wide approach. The first issue is whether a university-wide understanding of what is to be achieved via progress files is possible. The conflict between preparing for employment and learning in a discipline is the essence of this difficulty. East (2005) sees this articulated in the different skills frameworks, that is, the generic frameworks of Edexcel and QCA versus the more specific skills to be achieved within a discipline as described in the UK's Subject Benchmarking statements. He suggests that scepticism about 
'the skills agenda' is a disincentive to staff engagement in the PDP process whereas a focus on reflection to improve learning within a particular discipline may be more acceptable to academics.

\section{Analysis of case study one: employment}

In this case study progress files are firmly linked to the key skills agenda. Skills are perceived as attributes that can be transferred from one context (university) to another (the workplace). This approach can be seen as response to employer complaints that graduates are not fit for purpose, that is, adequately prepared with the skills needed in the workplace (Mason et al., 2003; Saunders and Machell, 2000). The progress file here is a record of achievement in which students are encouraged to evidence key skills for employment, that is, communication, numeracy, information technology and learning how to learn.

This model has significant flaws, not least its unpopularity with both students and staff (East, 2005). The progress file, particularly when seen in conjunction with the QCA key skills initiative (QCA, 2004), can be seen as a tool imposed by government with the intent of making higher education more narrowly focused on producing efficient workers. The progress file can be interpreted as another step towards 'performativity' in contemporary higher education, 'from a curriculum for inner contemplation to a curriculum for outer performance' (Barnett, 2000: 261). As such it will be resisted by some academics because they have a different view on the purpose of higher education. This version of the progress file does not articulate their concept of learning. Moreover, social practice theory suggests that a skills base approach is flawed. Skills such as communication, team working and problem solving are intimately bound to specific social practices and localized knowledge (Holmes, 2001). They cannot be learned out of context or transferred to a new context intact. New graduates in employment will need effective induction policies which provide opportunities for legitimate peripheral participation and assimilation into a new community of practice (Lave and Wenger, 1991). It is unlikely that a tick list of skills accomplished will be useful in this process unless the practices in which the skills were embedded have relevance to the career in question (Holmes, 2001). Rather than producing a checklist for students to identify their skills deficit, staff time might be better focused on designing curricula within which students would be able to demonstrate skill performance in authentic career relevant practices.

\section{Case study two: academic}

This was a funded project concerned with developing and embedding reflective portfolios in Geography (Kneale, 2002). It was part of a DfEE 
funded initiative, 'A strategic model for developing methods and materials for recording achievement in traditional universities'. Activity was coordinated by the Centre for Recording Achievement across consortia of pre-1992 universities. PDP was seen as vehicle for reflection on what had been achieved and for action planning, that is, looking back over the previous semester to evaluate learning and looking forward to the next to make constructive plans. Reflection here is on achievement within the course so it can be said to have an introjective identity, though the author notes that encouraging more mature reflection skills is seen as part of professional preparation for work in academia or elsewhere. Within the larger project, a suite of portfolios was developed to meet different departmental and professional needs. These ranged from recording professional development to generic skills-based portfolios. This case study report focuses on geography. The orientation was generic to the extent that it was a facultywide initiative that built on existing good practice in tutorial support yet singular in that a key purpose was to encourage deeper thinking on and around the subject area and to improve academic learning within the discipline. Any long-term benefits were seen as a bonus.

The expressed benefits of the progress file were also introjective, that is, not seen as preparing students to be more effectively equipped for 21 st-century employment but rather as a useful tool to help cope with the increasing diversity of student intake and limited time for one-to-one tutorial support. In its intention to help students understand and take responsibility for their own learning, it formalized the processes of individual objective setting. Different sections of the progress file were to be completed in advance of tutorials. This set the agenda for discussion with the tutor and so made better use of tutorial time. It also created an impression of equity across the student group. These tutorial practices were reinforced by email reminders to both students and tutors from the progress file coordinator.

The process was not assessed so levels of engagement varied and there was a reported gender and age bias; mature students and females were more likely to engage. The benefits were most notable in orientating students to the requirements of the course and helping them get organized. Another advantage was the effect on the interaction during a tutorial. The use of the reflection tools helped to create a more student-centred focus to the meeting. This empowerment of students through well designed self assessment tools has been observed elsewhere (Haigh, 2006). Despite these advantages there was concern that the students were not using the tool effectively to improve performance and this was linked to the lack of commitment to a reflective approach by the tutors and a tendency to view the progress file as a CV preparation tool. Thus there is a discrepancy between the aims of 
enthusiasts leading the implementation process and the day to day practices of academics interacting with students.

\section{Analysis of case two: academic}

This version of the progress file is more focused on developing meta-cognitive skills to improve deep learning in the discipline than on developing key skills for employment. This appears to be more motivating for students than generic skills training and therefore has the potential to help develop self-regulated learning (Boekaerts, 1999; Zimmerman, 1989). Clegg and Bradley (2006b) suggest that paradoxically the most 'academic' disciplines in their study, whilst placing key skills firmly in the context of improving learning in the discipline, may be producing the most employable graduates in terms of their written communication and presentation skills. These disciplines also seem to have well established personal tutor systems whose role is to encourage students to think about and record their learning processes. This model of personal tutoring may prove impossible to replicate in other courses where arguably student need for such support is more pronounced (East, 2005).

However even in settings with good personal tutor provision, staff and student engagement in PDP is patchy (Kneale, 2002). There is also no clear evidence that the professed aim of encouraging deep learning is achieved through PDP (Clegg and Bradley, 2006b). Broadfoot (1998) argues that the enlightenment ideal of deep learning in a particular discipline is already compromised by the assessment culture in contemporary higher education. In such a culture students are rewarded for playing the system rather than for deep self-motivated learning. In such an assessment-driven culture a nonassessed process of PDP will struggle to engage either students or tutors. On the other hand, Haggis (2003) makes the point that students struggle to understand what is expected in a particular discipline so are not able to engage in deep self-motivated learning without guidance. She argues for a view of academic study as an apprenticeship into new ways of thinking and expression. This perhaps takes the debate even further from the idea of key skills for employment towards the development of the enlightened thinker and communicator.

\section{Case study three: professional}

This two-year funded research and development project led to the production of a Reflective Progress File for dental therapists (Fry et al., 2002; Pee et al., 2000) which clearly corresponds to the professional model described by Clegg and Bradley (2006b). The paper-based file contained sections for recording achievement and activity sheets to promote reflective writing and 
self-appraisal. A reflective diary was added after the first trial at the request of participants. This consisted of a daily record of important events and weekly consideration of concerns and intentions arising. Group sharing and disclosure to tutors was encouraged. The identity displayed was projective in that the purpose was to record and review individual progress towards becoming a competent health care professional and indeed the progress file spanned training and professional practice. The authors specifically link progress files to other requirements of professional life, that is, evidencing and assessing continued fitness to practice and the need for continuing professional development. The orientation was singular in that the file was embedded in the curriculum and one of the key aims was to promote the professional role and competencies of the therapists to their employers.

\section{Analysis of case study three: professional}

The projection and singularity of this version of the progress file perhaps goes some way to explaining the mixed reception of the tool from different groups. Practising therapists evaluated it very positively as a tool to support development within their role whereas an adaptation of the tool trialled by undergraduate dental students (not therapists) was very unpopular. From the self-regulated learning perspective it can be seen that the therapists had much clearer personal and professional motivation to use the file. Professional courses can be seen to have an advantage in the development of progress files in that their students have a clear focus on employment requirements from the beginning of the course and there is a strong tradition of reflection on practice embedded in the curricula (Brennan and Shah, 2003; Clegg and Bradley, 2006a). The focus on practices rather than skills is also relevant. Holmes (2001) proposes an alternative approach to the skills agenda which focuses on practices and identity, that is, skills should not be see as generic tools which an individual carries with them - skill is a generalized way of articulating what a person can do in a particular social context. From this perspective recording and reflecting on performance in practice settings is clearly good preparation for employment.

The limitation of this approach is that it can lead to a conformist approach where the goal is to be seen to perform appropriately by significant others responsible for validating the performance. Reflection can be limited to how far the student is conforming to work-based protocols and evidencebased practice. To infer that professional programmes are already encouraging reflection and therefore meeting the requirement for PDP is perhaps missing an opportunity to create a pedagogic device that promotes selfawareness and lifelong learning, developing the potential to act on the world as well as in it. 


\section{Discussion}

On the basis of this albeit limited evidence, it appears that the implementation of progress files can be described in terms of tendency towards one of three ideal types: professional, academic or employment. The concepts of introjection/projection and singular/generic orientation go some way to explaining the different approaches. The differences may also reflect variation in the shared meaning of learning in particular contexts. The progress file is an artefact which articulates the priorities of a particular activity system. These may be reflection on professional practice, promotion of deep learning in a discipline or developing and recording skills needed for employment.

It is suggested here that all three are examples of academics learning through experience about the process of personal development planning and how this integrates with their current educational provision. So these early versions of progress files clearly reflect the context in which they are situated. Brennan and Shah (2003) report that existing practice on implementation of progress files is rather conservative so far but it could be argued that new initiatives which can build on existing practices and beliefs have more chance of successful implementation (Clegg and Bradley, 2006b) and new artefacts produced by these initiatives in turn influence and modify existing practices and beliefs. Thus early versions of progress files can be seen as a stage which may lead to more radical change in practice.

The purpose of higher education, even within a particular institution, can be described as a contested object (Blackler and Regan, 2005) and the different 'ideal types' of PDP provision reflect different conceptions of that purpose. Saunders and Machell (2000) use case study data to suggest that different universities have responded differently to key skills policies. Older established universities which attract more traditional students focus on the development of academic skills, whereas newer institutions (in the UK these are known as 'the post-1992 universities'), working with a more diverse student group, focus on employability. This divide is also likely to be evident in progress file implementation. The question is whether the implementation of PDP policies will reinforce differences or lead to greater consensus on the purpose of university education in the 21 st century. An activity theory perspective (Engeström, 2001) may be a useful framework for researching developing understandings of the progress file particularly in the context of new e-portfolio tools.

The deceptively simple concept of the progress file becomes increasingly complex as one tries to implement it in practice. Advocates of personal development planning suggest numerous advantages for the student (Croot and Gedye, 2006) and psychological research confirms the benefits 
of self-regulated learning (Zimmerman, 1989). However, in order to realize these benefits it is essential that PDP is integrated into the academic process. Staff engagement is seen as key to successful implementation. This is more likely where PDP is promoted as a tool to improve learning in the discipline rather than focusing on employability per se. Some would argue that the graduate skills achieved through full engagement in an academic programme will develop the autonomous learner able to think creatively and work collaboratively. Lack of engagement and surface learning to meet heavy assessment loads will work against this development (Broadfoot, 1998) as will failure to provide supported induction into the ways of thinking and knowing in the discipline (Haggis, 2003).

Another obstacle to integrating PDP into the academic process is inadequate resources. East (2005) makes the point that implementation of PDP using a personal tutor system can make excessive demands on tutor time, and that time available for such support seems inequitably distributed between different universities. Kneale (2002) believes that progress file preparation makes tutorials more focused and effective in the context of an established personal tutor system. A module approach to PDP may be more effective in universities without an established personal tutor system. This is likely to be less demanding on tutor time particularly where the module leader utilizes student peer-to-peer support. East (2005) provides evidence that a PDP process can be made available to students without undue erosion of staff time through a dedicated module using peer support and structured group activities instead of one-to-one tutorials. However the challenge in the modular approach is to make the activity purposeful in the context of the whole curriculum.

In this process of experimentation with the concept of progress files we are hopefully reaching a more sophisticated understanding of the relationship between education and employment, PDP and skills. There is an urgent need for more action research and evaluative studies to determine the usefulness of progress files in the academic process. The situation is still in a developmental stage and it is likely that new influences such as e-portfolio and personal learning systems will have a significant impact on future progress file policies. The integration of progress files into the academic process so far is patchy and arguably superficial. There is little evidence to date that this tool is being widely used. However there are pockets of good practice where progress files are used to facilitate the reviewing, action planning and presentation of individual learning journeys (Jackson and Ward, 2004). Realizing the ambition to bring about sustainable implementation in different contexts will require commitment, experimentation and adequate resources. If these are forthcoming, the progress file may become an artefact which supports a student-centred vision of higher education that 
prepares students more effectively for life-long learning and the challenges of the 21 st century.

\section{References}

BARnett, R. (2000) 'Supercomplexity and the Curriculum', Studies in Higher Education 25(3): 255-65.

Bernstein, B. (2000) Pedagogy, Symbolic Control and Identity: Theory Research, Critique. Oxford: Rowman \& Littlefield.

Blackler, F. \& Regan, S. (2005) 'The Conflicted Object; Strategy as Organisational Practice', Lancaster University, paper submitted to the Journal of Management Studies, April.

BOEKAERTS, M. (1999) 'Self-regulated Learning: Where We are Today', International Journal of Educational Research 31(6): 445-57.

BRENNAN, J. \& SHAH, T. (2003) 'Report on the Implementation of Progress Files',

Centre for Higher Education Research and Information, London.

BROADFOOT, P. (1998) 'Quality Standards and Control in Higher Education: What Price

Life-long Learning?’ International Studies in Sociology of Education 8(2): 155-180.

CHE (1963) Higher Education Report of the Committee appointed by the Prime

Minister under the Chairmanship of Lord Robbins 1961-3. HMSO.

ClegG, S. \& BRAdley, S. (2006a) 'The Implementation of Progress Files in Higher

Education: Reflection as National Policy', Higher Education 51(4): 465-86.

Clegg, S. \& BRAdley, S. (2006b) 'Models of Personal Development Planning: Practice and Processes', British Educational Research Journal 32(1): 57-76.

CROOT, D. \& GEDYE, S. (2006) 'Getting the Most Out of Progress Files and Personal

Development Planning', Journal of Geography in Higher Education 30(1): 173-9.

DFES (2003) The Future of Higher Education. London: HMSO.

EAST, R. (2005) 'A Progress Report on Progress Files', Active Learning in Higher Education 6(2): 160-71.

ENGESTRÖM, Y. (2001) 'Expansive Learning at Work: Toward an Activity Theoretical Reconceptualization', Journal of Education and Work 14(1): 133-56.

entwistle, N. J. \& Peterson, E. R. (2004) 'Conceptions of Learning and Knowledge in Higher Education: Relationships with Study Behaviour and Influences of Learning Environments', International Journal of Educational Research 41(6): 407-28. Fry, H., DAVEnport, E. S., Woodman, T. \& PeE, B. (2002) 'Developing Progress Files:

A Case Study', Teaching in Higher Education 7(1): 97-111.

Gibbons, M. (1998) 'Higher Education Relevance in the 21st Century', in UNESCO World Conference on Higher Education. Paris: World Bank.

GOUGH, D., KiWAN, D., SUtClifFe, K., Simpson, D. \& HOUGHTON, N. (2003) 'A

Systematic Map and Synthesis Review of the Effectiveness of Personal Development

Planning for Improving Student Learning', EPPI-Centre, Social Science Research

Unit, London, pp. 131.

HAGGIS, T. (2003) 'Constructing Images of Ourselves? A Critical Investigation into

“Approaches to Learning” Research in Higher Education', British Educational Research Journal 29: 89-104.

HAigh, J. (2006) 'The Impact of Mobile Technology on Students' Experience of Learning and Being Assessed in Clinical Practice: A Focus Group Study', unpublished paper, University of Lancaster.

holmes, L. (2001) 'Reconsidering Graduate Employability: The "Graduate Identity"

Approach', Quality in Higher Education 7(2): 111-19. 
JACKSON, N. \& WARD, R. (2004) 'A Fresh Perspective on Progress Files - A Way of Representing Complex Learning and Achievement in Higher Education’, Assessment \& Evaluation in Higher Education 29(4): 423-49.

Kneale, P. (2002) 'Developing and Embedding Reflective Portfolios in Geography', Journal of Geography in Higher Education 26(1): 81-94.

LAve, J. \& Wenger, E. (1991) Situated Learning: Legitimate Peripheral Participation. New York: Cambridge University Press.

mason, G., Williams, G., Cranmer, S. \& Guile, D. (2003) 'Graduate Skill Gaps and Employer-provided Training', How Much Does Higher Education Enhance the Employability of Graduates?, pp. 80-91. Higher Education Funding Council for England.

NATIONAL COMMITTEE OF ENQUiRY INTO HIGHER EDUCATION [NCEHE] (1997)

Higher Education in the Learning Society: Report of the National Committee, The Dearing Report. Middlesex: HMSO.

PeE, B., WOOdman, T., FRY, H. \& DAVenport, E. S. (2000) 'Practice-based Learning: Views on the Development of a Reflective Learning Tool', Medical Education 34(9): 754-61.

QAAHE (2000) 'Policy statement on a Progress file for Higher Education': http:// www.qaa.ac.uk/academicinfrastructure/progressFiles/default.asp [accessed 8 March 2005].

QAAHe (2001) 'Guidelines for HE Progress Files’, http://www.qaa.ac.uk/ academicinfrastructure/progressFiles/guidelines/progfile2001.pdf [accessed 29 January 2006].

Qualifications and CurRiculum authority (2004) 'Key Skills: Standards and Guidance': http://www.qca.org.uk/qca_6455.aspx [accessed 29 November 2007].

SAUNDERS, M. \& MACHELl, J. (2000) 'Understanding Emerging Trends in Higher

Education Curricula and Work Connections', Higher Education Policy 13(3): 287-302.

Winch, C. (2002) ‘The Economic Aims of Education', Journal of Philosophy of Education 36(1): 101-117.

Zimmerman, B. J. (1989) 'A Social Cognitive View of Self-regulated Academic Learning’, Journal of Educational Psychology 81(3): 329-39.

\section{Biographical note}

JACKIE HAIGH is a Senior Lecturer in Midwifery and Women's Health in the School of Health Studies at the University of Bradford. Her research interests include Personal/ Professional Development Planning and use of ICT to support teaching and learning in Higher Education.

Address: School of Health Studies, University of Bradford, Unity Building, 25 Trinity Road, Bradford BD5 0BB, UK. [email: J.Haigh3@Bradford.ac.uk] 